\title{
Por uma genealogia das rádios comunitárias brasileiras
}

\author{
Towards a genealogy of the Brazilian \\ community radios
}

\begin{abstract}
João Paulo Malerba | Universidade Federal do Rio de Janeiro
Professor e jornalista, é doutor em Comunicação e Cultura pela Escola de Comunicação da Universidade Federal do Rio de Janeiro (ECO/UFRJ), mestre e bacharel pela mesma instituição, tendo realizado parte de sua pesquisa de doutorado na University of Westminster (Londres, Reino Unido). É pesquisador no Laboratório de Estudos em Comunicação Comunitária (LECC/UFRJ) e membro da Associação Mundial das Rádios Comunitárias (AMARC Brasil), onde foi representante

nacional (2009/2011), coordenador executivo (2011/2013) e conselheiro político (2013/2015). E-mail: c: joaopaulorj@yahoo.com.br
\end{abstract}

\begin{abstract}
Resumo
$\mathrm{O}$ artigo se propóe a delinear as matrizes históricas da radiodifusão comunitária brasileira desde sua(s) gênese(s) até o processo de legalização (1990s). Isso foi feito a partir de análise documental e revisão bibliográfica crítica do que até então fora produzido. Realizamos uma breve descrição histórica de cada uma das vertentes - eclesiástica, livre e comunitária - para propor uma discussão que permita compreender a real heterogeneidade da radiodifusão comunitária brasileira.
\end{abstract}

Palavras-Chave: História; Rádios comunitárias; Comunicação Comunitária.

\begin{abstract}
The paper proposes to outline the historical matrices of Brazilian community broadcasting from its genesis to the process of legalization (1990s). This was done from documentary analysis and critical bibliographic review of what had been produced up to today. We present a brief historical description of each one of the lineage - ecclesiastical, libertarian and communitarian - to propose a discussion to understand the real heterogeneity of Brazilian community broadcasting.
\end{abstract}

Keywords: History; Community radios; Community Communication. 


\section{Introdução}

No que se refere à América Latina, seja qual for o enfoque levado em conta - pioneirismo histórico, proporção numérica, incidência política, representatividade social -, as rádios comunitárias se destacam, quando comparadas aos seus pares no mundo. Na sua pesquisa mundial, Mendel (2013) a considera "o local de nascimento da rádio comunitária", numa "região que tem sido caracterizada pelo alto grau de concentração de propriedade dos meios, cujos donos têm relações próximas com o negócio e elites políticas” (p. 39).

$\mathrm{Na}$ análise sincrônica que fez da radiodifusão comunitária latino-americana, Pulleiro (2011, p. 44) percebe que os estudos sobre o fenômeno sintetizam sua gênese em duas vertentes: uma de emissoras impulsionadas e geridas por organizaçóes ligadas à Igreja Católica de propósitos educativos e evangelizadores e outra referente às experiências incentivadas ou diretamente ligadas a organizaçóes políticas e sindicais de macroprojetos de transformaçáo social e política e que faziam dos meios instrumentos de comunicação ${ }^{1}$. Ao longo do processo histórico, fruto da articulação e da mobilização popular, experiências de ambas vertentes seriam investidas de perfil político próprio. Pulleiro chama de comunitária uma "terceira grande vertente inicialmente influenciada pelas experiências vindas do Canadá e Europa” (p. 85). Nesse sentido, a principal responsável para que a ideia de comunidade via rádio fosse "transferida [trasladada] a América Latina" (idem, grifo meu) foi a Associação Mundial de Rádios Comunitárias (AMARC), criada em 1983, mas com maior incidência na América Latina a partir dos 1990, quando abre sede própria na região.

Ainda que não negue totalmente a tendência regional, o caso brasileiro tem especificidades: primeiramente, entre nós houve um importante protagonismo da apropriação juvenil, libertária e estudantil do veículo rádio a partir dos anos 1970/80; além disso, nossa vertente católica desempenhou papel essencial na organização sindical e partidária rural (e vice-versa), e; por fim, os sindicatos urbanos e partidos políticos demoraram a incorporar a solução rádio para orquestração da ação política ${ }^{2}$. Isso foi se dar (e de forma incipiente) no mundo sindical ${ }^{3}$ e partidário ${ }^{4}$ somente a partir de meados dos anos 1980 e, principalmente, como fruto da iniciativa e das críticas da vertente juvenil. Por exemplo, na opinião de Leo Tomaz, da pioneira emissora livre Rádio Reversão, a maior dificuldade para a eclosão do movimento "não residia somente na repressão militar ou na falta de verbas para compra de equipamentos, que nesta época já eram consideravelmente baratos, mas sim na ideologia 'aparelhista', 'ruralista', dos partidos de esquerda no Brasil” (ANDRIOTTI, 2004, p. 20). Só em fins dos 1980 e começo dos 1990 é que sindicatos urbanos e partidos políticos passam realmente a encampar a luta do já então organizado movimento de rádios livres e comunitárias.

Desse modo, a partir de nossas pesquisas e em diálogo com as descobertas de Pulleiro, podemos sintetizar em três as principais vertentes que constituem a história da radiodifusão comunitária brasileira: eclesiástica, livre e comunitária. 


\section{Vertente eclesiástica: popular e de base}

Um dos germens políticos da rádio comunitária brasileira deve ser investigado no uso que uma ala mais progressista da Igreja Católica fez do veículo com fins educativos e de mobilização social. Seus antecedentes estão nas "experiências de educação pelo rádio por bispos brasileiros na Região Nordeste, principalmente no Rio Grande do Norte e em Sergipe, nos anos de 1950" (FÁVERO, 2004, p. 1). A partir da mobilização daqueles bispos, em março de 1961, é fundado o Movimento de Educação de Base (MEB), uma experiência única de educação não formal à distância e conscientização política desenvolvida por dioceses do Nordeste (depois ampliado para Norte e Centro-Oeste), em torno da criação de escolas radiofônicas: no seu auge, em 1963, eram 7.353 delas permitindo que 320 mil alunos concluíssem o ciclo de alfabetização em cinco anos.

No início, o MEB contava com apoio, inclusive financeiro, do governo federal: no amplo acordo conservador do nacional-desenvolvimentismo, a Igreja se aliava ao Estado "na difusão da ideologia da ordem e da segurança" contra "ideologias estranhas" que pudessem afetar a hegemonia do poder dominante (idem, p. 5). Mas o MEB surge numa Igreja também marcada pelas ideias ecumênicas e de esquerda de João XXIII e num Brasil de organização crescente dos trabalhadores rurais em sindicatos. As forças que se opunham na Igreja se acirraram em meio à efervescência política da época e os resquícios conservadores e a prioridade da evangelização foram abandonados já no primeiro encontro nacional. $\mathrm{O}$ MEB passa por uma redefinição radical: seu objetivo, então, vai explicitamente ser a "transformação de mentalidades e estruturas" a partir da "educação de base como processo de autoconscientização das massas" e que parta "das necessidades e dos meios populares de participaçáo, integrados em uma autêntica cultura popular, que leve a uma ação transformadora" (MEB, 1962). O perfeito casamento da visão marxista sobre a "consciência histórica e comunicação das consciências como característica fundamental da história e da dialética fundada nessa comunicação de consciências" (FÁVERO, 2004, p. 7) com a pedagogia libertadora e autonomista de Paulo Freire, adotada amplamente pelo MEB, desembocaria na politizaçáo de seus métodos e materiais pedagógicos.

Frases desse material ecoaram pelas ondas do rádio do Brasil profundo: "um povo só marcha para a libertação, quando caminha com sua cultura" (MEB, 1963, p. 48); "a uniāo faz a força do sindicato" (p. 42); "o povo tem o dever de lutar por justiça” (p. 54); "é preciso mudança completa no Brasil” (p. 32). Não é de estranhar que dois meses antes do golpe de 1964, o material tenha sido apreendido e sua utilizaçáo proibida. Esse seria o estopim para uma campanha contra os bispos progressistas e um controle ideológico que, dali em diante, enfraqueceria a radicalidade política do MEB. De todo modo, o resultado prático daquele primeiro quinquênio não está somente na continuidade do projeto, que até hoje gera frutos ${ }^{5}$. Daquelas ondas há uma reverberação simbólica difícil de quantificar, mas facilmente intuída nas experiências posteriores de radiodifusáo comunitária e de outros movimentos sociais. 
Primeiramente, há que se destacar o legado quanto à estrutura e mobilização comunitária resultante e necessária para o processo educacional do MEB. Festa (1986), no estudo que realizou sobre as CEBs, destaca o papel da Igreja no trabalho de conscientização das classes trabalhadoras pós-golpe, que "ampliava os ensinamentos da etapa anterior e assimilava, com outras características, a proposta de Paulo Freire aliada aos ensinamentos de Gramsci” (p. 18). Como se sabe, o enfoque libertador e autônomo da pedagogia freireana tem como base uma relação horizontal e participativa entre educador e educando, entendidos como corresponsáveis de um mesmo processo de construção do conhecimento. A aplicação dessa metodologia gerava uma integração simbólica dos membros num todo coerente de uma partilha comum: "as CEBs por sua constituição que privilegiava a fala, a relação interpessoal, a formação de seus participantes a partir da convivência fraterna e cotidiana, constituíram-se no maior espaço de comunicação" (FESTA, 1986, p. 19) nos moldes da hominização freireana. Para além de sua própria máxima que "a educação é comunicação e diálogo" (FREIRE, 2002, p. 52), o método freireano tem em suas bases a mesma comunicação dialógica, crítica e horizontal das experiências comunitárias em comunicação. Ou vice-versa. Inspirados nas CEBs, diversos movimentos sociais e organizaçóes comunitárias trouxeram, direta ou indiretamente, a influência de Freire e suas teorias. No caso da Comunicação Comunitária, Cogo (2009) chega a afirmar que "a concepção freireana de educação é a principal inspiradora de experiências de comunicação alternativa e popular que se desenvolvem no meio urbano vinculadas a movimentos sociais, sindicais e CEBs nas décadas de 70 e 80 ".

No nível organizacional, a partir de 1982, a União Cristã Brasileira de Comunicação (UCBC) passaria a priorizar "a necessidade das comunidades organizadas possuírem seus próprios meios de comunicação, inclusive rádios” com "um projeto social de comunicação e não um projeto católico" (ANDRIOTTI, 2004, p. 54) e incidir para tal na Constituinte. A UCBC, na verdade, refletia uma mudança orgânica da postura da Igreja com relação às radioescolas em que a autonomizaçáo freireana parece ter sobredeterminado, desde a base, a estrutura eclesiástica: ora, a tomada da palavra e o despertar da consciência crítica só se completariam com a apropriação popular das radioescolas como ferramenta de ação política. A "entrega" dessas radioescolas fica expressa sob um jargão (paternalista e nada autonomista) atribuído aos bispos progressistas da década de 1970 e que ainda perdura: "dar voz aos que não têm voz".

Já no nível molecular, por exemplo, Denise Cogo (1998), ao apresentar um histórico do uso dos alto-falantes como emissora comunitária no Brasil, descobre o pioneirismo no interior das CEBs da Zona Leste de São Paulo. Já em 1983, na região de São Miguel Paulista, as primeiras cornetas foram fixadas no centro comunitário da favela Nossa Senhora Aparecida e no alto da igreja. Dois anos depois a região já teria seu $1^{\circ}$ Encontro de Rádio Popular e contaria oito rádios de alto-falantes; em 1987 esse número chega a 42, praticamente todas instaladas em igrejas. A partir daí, os idealizadores da região organizariam cursos locais para comunicadores populares e passariam a assessorar grupos do Rio Grande do Norte, Piauí, Mato Grosso, Rio de Janeiro, Rio Grande 
do Sul. Cogo também identifica experiências de radiocorneta em Fortaleza, lá chamadas radiadoras, uma já no início da década de 1970 e outra meia dúzia em 1987. Três anos antes, Recife tem sua primeira radiocorneta e na década seguinte, outras duas dezenas são instaladas. Também o livreto Como montar uma rádio comunitária (TREVISAN e PRADO, 1998) conta "de um pequeno sistema de Rádio Comunitária com Alto-falante” instalado, em julho de 1994, no bairro do Novo Horizonte, em Macapá (PA) que, "com o apoio da Pastoral da Comunicação e Pastoral da Criança" viria a se tornar a Rádio Comunitária Novo Tempo (p. 22).

Podemos afirmar que, pelo menos até a década de 1990, a maioria das experiências radiofônicas cidadâs de caráter de base foi protagonizada por movimentos sociais ou comunitários que contaram com o apoio e/ou influência da Igreja Católica. Devemos atribuir tal atuação ao ânimo político de suas parcelas progressistas, e também à expertise acumulada com as radioescolas, às CEBs e ao seu caráter-rede.

O caráter eclesiástico, popular e de base aparece nos dois casos considerados pioneiros, surgidos ambos antes da lei de radiodifusão comunitária. Em 1981, nasce a Rádio Favela (Belo Horizonte, Minas Gerais) desde o "Aglomerado da Serra para o mundo", fruto da mobilizaçáo de jovens interessados em divulgar a cultura da favela, discutir desigualdades raciais e injustiças sociais e... fazer rádio. Imortalizada no filme Uma onda no ar (2002), de Helvécio Ratton, sua história conta com a "ajuda da Igreja Católica e da associação de moradores” (NUNES, 2007, p. 103). A voz da favela foi calada por várias apreensóes policiais, sempre mudando o transmissor de lugar a cada nova investida. A regularização aconteceu uma década depois, como rádio educativa.

No caso de uma rádio que também reclama pioneirismo e tem incontestável importância na constituição do movimento brasileiro, a mobilização inicial da Rádio Novos Rumos (Queimados, RJ) partiu de "um pequeno grupo de pessoas ligadas à Igreja, ao bairro e a partidos políticos”, entre elas, Tião Santos, que viria a ser o primeiro coordenador da Associação Brasileira de Radiodifusão Comunitária (ABRAÇO) e Ismael Lopes, futuro secretário da associação. Esse grupo reuniu recursos e instalou uma emissora experimental de 20 watts ali, na Baixada Fluminense, uma região que até hoje registra altos índices de criminalidade e serviços públicos precários. Ao primeiro fechamento, em maio de 1991, se seguiu uma corajosa mobilização com direito a um abaixo-assinado por dez mil pessoas, protesto de rua e um manifesto em que defendem que "as leis e a Justiça devem existir para servir ao povo e não para oprimi-lo. Se há uma lei que impede a criação de uma rádio de âmbito local, popular e democrática, administrada pela comunidade, é essa lei que tem de deixar de existir e não a nossa rádio" (COELHO NETO, 2002, p. 27). Depois de ser fechada diversas vezes e reaberta sempre com a mobilização da comunidade, sua outorga só sairia em 2009, quando já era a terceira rádio mais ouvida de Queimados. 


\section{Vertente livre: juvenil e universitária}

Ao contrário do que se costuma dizer, a outra vertente originária das rádios comunitárias brasileiras é também política. Ainda que partíssemos de uma visão restrita do conceito, não se pode negar o deslocamento de poder inerente à utilização não autorizada do espectro eletromagnético: mesmo a experimentação radiofônica mais inocente é ressignificada política e verticalmente no momento em que o Estado reprime e nega um direito humano fundamental que, ao contrário, deveria promover. Nesse sentido, são emblemáticos os desdobramentos da primeira transmissão radiofônica livre juvenil que se tem registro no Brasil: em fevereiro de 1971, o capixaba Eduardo Luiz Ferreira Silva, na época um adolescente de 16 anos aficionado por eletrônica, instala no banheiro do bar do pai a Rádio Paranoica. Dos 15 watts iniciais, ele e o irmão turbinam para 300, atingindo toda Vitória (ES). Mas o experimento durou seis dias e acabou de forma violenta: os policias quebraram o bar todo e prenderam clientes, Eduardo, seu pai, além de apreenderem os equipamentos, "livros, cartazes e rasgarem os colchôes procurando alguma coisa” (NUNES, 1995, p. 65). Era plena ditadura, governo Médici: Eduardo ficou preso um dia e o pai, três, enquanto vasculhavam sua vida buscando ligaçóes políticas. Em 1994, quando pediu vistas ao processo, descobriu que alegaram "que a rádio era uma armação dos comunistas para desestabilizar o regime". De todo modo, aquela experiência selaria o seu destino: viria a se tornar engenheiro e professor de eletrônica, radioamante e militante: "a comunicação precisa ser democratizada e trabalho por isso. Ensino a fazer transmissores, monto rádios no interior, em Ondas Curtas, o formato ideal para objetivos de comunicação popular. Já ajudei a montar mais de 80 emissoras em todo o país, tudo no interior" (idem, p. 66).

Se a Paranoica surgira de uma ação isolada, a explosão das rádios livres brasileiras nasce orquestrada e com diagnóstico político. Um dos autores do livro que se tornaria a bíblia das livres brasileiras (Rádios livres: a reforma agrária no ar, MACHADO et al., 1986), em mesa redonda com Félix Guattari, na capital paulista, em 1982, diagnosticava: "os problemas para uma eclosão das rádios livres no Brasil não são apenas de natureza policial. Há uma resistência interna imensa dentro dos próprios grupos de esquerda. Seus programas simplesmente ignoram a questão da mídia” (GUATTARI e ROLNIK, 1986, p. 111). Filósofo, participante da Radio Tomate e pivô do movimento francês, Guattari voltaria outras vezes para incentivar nosso movimento e inclusive prefaciaria o livro de Machado, Magri e Masagão. Na ocasião, respondera que o mesmo se dera na França, onde "trotskistas, maoistas e esquerdistas de toda natureza foram os últimos a encarar as possibilidades abertas pelas rádios livres” (p. 111).

$\mathrm{Na}$ importante recuperação histórica que fez do movimento, Marisa Meliani Nunes em Rádios livres: o outro lado da Voz do Brasil (1995) defende que seu antecedente seria o verão de 1982, em Sorocaba, "que contou com mais de 100 emissoras no ar, com 43 comprovadas". Os antecedentes lembram a Paranoica: isolada, adolescente e experimental: assim nasce a Rádio Spectro, quando, em 1976, um garoto de 14 anos segue o passo a passo de uma revista de eletrônica e constrói um transmissor que primeiro chega à casa do vizinho 
até, gradualmente, alcançar $10 \mathrm{~km}$ de raio. Como viralidade é marca das livres, "até o final de 1981, já estão no ar as rádios Estrôncio 90, Alfa 1, Colúmbia, Fênix, Star e Centauros. A Centauros muda de nome para Voyage e se junta à Spectro para formar a mais popular rádio livre de Sorocaba: a Spectro Voyage Clandestina-SVC". A fala de um de seus participantes à imprensa demonstra uma politicidade embrionária: "nossas rádios são uma revolta contra o monopólio das FMs. O governo brasileiro vai ter que abrir um espaço para as rádios piratas" (NUNES, 1995, p. 67-68), ou seja, liberar uma faixa do espectro para transmissão livre e não comercial.

A segunda fase é iniciada quando um transmissor montado numa panela e escondido no Centro Acadêmico de Ciências Sociais da PUC, em 20 de julho de 1985, emite estas primeiras ondas: "Rádio Xilik. Rádio livre urgente, em 106.4 MHz, aberta a todos, exceto a generais ativos e passivos, senhoras de Santana, falsários, mamães que dizem sempre mentirinhas, falocratas, crianças que falam sempre a verdade, demagogos, juízes evangélicos” (MACHADO et al., 1986, p. 50). Já não se trata mais de uma "iniciativa isolada", mas organizada e querendo impulsionar um movimento de rádios livres. Antes de entrar no ar, seus idealizadores (autodenominados "doze apóstolos”, entre eles o professor Arlindo Machado, Caio Magri e Marcelo Masagão) avisam alguns dos principais meios de comunicação do país (Folha de S.Paulo, O Estado de S. Paulo, Jornal da Tarde, Veja, IstoÉ), a ponto de André Picardi, o "Sombra da Xilik", afirmar que "a rádio era mais lida do que ouvida". O objetivo é provocar o Dentel (Departamento Nacional de Telecomunicaçôes, então o órgão fiscalizador), pautar o tema da democratização da comunicação e da "ideia de rádio livre a uma parcela considerada 'formadora de opinião"' com foco nos princípios de desobediência civil e negação de qualquer solução legal, considerada "reprodução do controle sobre a comunicação" e contrária à "sua verdadeira funçáo dentro da democracia" (NUNES, 1995, p. 71). Um mês depois, os doze apóstolos, boa parte da PUC-SP e USP, organizam a segunda visita de Guattari, cuja palestra lota o Pátio da Cruz, na universidade católica e eletriza os mais de 600 presentes para "que mil transmissores floresçam", lema do movimento. A presença de Guattari náo poderia ser mais pertinente, dado que linguajar, ideário e estética das livres paulistas bebiam dos movimentos de rádios livres italianas e francesas.

O movimento brasileiro explodira pós-Xilik. De acordo com informaçôes fornecidas por seus próprios idealizadores, já em 1986, elas pipocavam em outros estados:

uma em Salvador, na Bahia, a Estaçâo da Luz, ligada ao movimento gay; uma em Goiânia, ligada ao movimento dos Posseiros Urbanos; uma em Santos, a Baixada Alternativa; duas em Fortaleza, uma do movimento ecologista, a outra de estudantes da Universidade Federal; duas em Vitória, no Espírito Santo, a Radialética e a Jovem Clān; uma em Petrópolis, estado do Rio, a Estúdio FM. (NARAH, 1988, p. 177).

Em São Paulo, o próximo passo foi conformar a Cooperativa de Radioamantes (CORA-Livre): seu manifesto fala da construção de "uma ética das rádios livres, que discorra sobre os limites de potência do transmissor, interferência de sinais", mas sem abrir mão da "invasão e ocupação definitiva da 
atmosfera (MACHADO et al., 1986, p. 23). A CORA-Livre cria uma rede de proteção e replicação: com transmissores emprestados da Xilik, nascem Ítaca, Totó Ternura, Molotov, inclusive a Ermelino Matarazzo, na favela de mesmo nome, ainda que a "maioria [surja] por iniciativa de estudantes universitários, que transmitem não só para o meio acadêmico, mas também para bairros e comunidades" (NUNES, 1995, p. 76). Diferentemente do de muitos de seus pares, o fim da Xilik não foi via repressão estatal, mas por comum acordo do grupo, depois de já deflagrado o movimento e, assim, cumprido seu objetivo. Até houve duas tentativas de fechamento, mas seriam frustradas com a ajuda de Dom Paulo Evaristo Arns, cardeal de São Paulo e grão-chanceler da PUC, morada da rádio.

Não demoraria para a febre contagiar a outra megalópole brasileira: "os radioamantes do Rio de Janeiro e São Paulo resolveram se encontrar para fortalecer, se conhecer e 'trocar figurinhas'. Foi em 1986, no Circo Voador, na cidade do Rio de Janeiro, e deste encontro surgiu a ABOLA (Associaçáo Brasileira pelas Ondas Livres), que não conseguiu avançar” (CEMINA, 2000, p. 38). O que não impediu que nos anos seguintes surgissem a Rádio Pop-Goiaba (UFF), Tan-Tan (Macaé), Interferência (UFRJ). Enfim, modelar para as que floresceriam depois, assim nasce o movimento de rádios livres brasileiro: jovem, universitário, de inspiração europeia e libertária, politizado e multiplicador.

Porém, multiplicação em amplitude gera muitas espécies: "os militantes anarquistas brasileiros logo se apaixonam pela ideia e utilizam o rádio para divulgar suas ideias libertárias" (NUNES, 1995, p. 94). Tendo como palavras de ordem "autonomia diante do Estado e a ação direta", no município de Poá (Grande São Paulo), em 1988, florescem as anarquistas Apache e Tuareg: "varamos o monopólio das comunicações, atropelamos os medievais caciques locais com suas 'rádios populares" (in NUNES, 1995, p. 94). Essas e demais rádios anarquistas participaram do movimento nacional até "o momento em que sentem que as associaçóes não pretendem tomar um rumo autogestionário, com uma participação efetiva de todos" (idem, p. 95): por rejeitarem vínculos representativos, partidários e religiosos, elas vão se afastando do coletivo de acordo com que as livres passam a abarcar uma multiplicidade cada vez maior.

E é de carona nesse boom que igrejas evangélicas foram "tomando conta do dial, reproduzindo-se com uma velocidade espantosa (...) [algumas] já trabalham articuladas com a bancada evangélica do Congresso", como avaliou Meliani Nunes. Em sua pesquisa, relata dificuldades para entrevistar "rádios livres evangélicas", que "formam um grupo fechado, quase à parte de todo o movimento de rádios livres", ainda que algumas "se juntem ao movimento pela democratização da comunicação" (1995, p. 90).

Seu crescimento se expressava em números: quando, em abril de 1991, é criada a Associação das Rádios Livres do Estado de Sáo Paulo (ARLESP) por 10 rádios, quatro eram evangélicas, além de anarquistas, petistas e culturais. Numa amostragem feita de março de 1994 a fevereiro de 1995 na Zona Norte de São Paulo, Nunes identificou 50 emissoras livres: " $44 \%$ têm caráter religioso/evangélico, 24\% comercial/musical, 24\% cultural (...) Do total, 68\% têm fins lucrativos, $24 \%$ são sem fins lucrativos e $8 \%$ não foram identificadas" (NUNES, p. 107). 


\section{Vertente comunitária: cidadã e plural}

Em 1983, representantes de cerca de 600 rádios e ativistas de 36 países, reunidos por ocasião do Ano Internacional das Comunicaçóes, promovido pela ONU, fundam simbolicamente a entấo nomeada Associaçáo Mundial de Artesãos da Comunicação, em Montreal, no Canadá. Ela viria a se tornar uma associação três anos depois, na 2a Conferência em Vancouver e seria reconhecida como organização não-governamental internacional na $3^{\text {a }}$ Conferência em Manágua (1988).

Ainda que juridicamente seja uma ONG internacional, a AMARC se organiza como rede e se estrutura como associação, cujas decisões são tomadas em assembleias mundiais, regionais e nacionais. Mais ou menos a cada quatro anos é realizada uma Assembleia Mundial, aberta à participação de todos os associados e onde se discutem e definem as grandes metas do movimento para a gestão eleita. Ali são aprovadas as novas associações em nível mundial e é eleito um Conselho Internacional, composto pela presidência mundial e os chamados vice-presidentes, ali referendados, mas anteriormente eleitos em cada uma das macrorregióes em que se organiza a AMARC: América do Norte, América Latina e Caribe, Europa, África, Oriente Médio e Ásia-Pacífico. Em nosso continente a entidade se subdivide em seis sub-regiôes: América Central, Caribe, México, Países Andinos, Cone Sul e Brasil. Cada sub-região indica um representante para compor o Conselho Regional da AMARC América Latina e Caribe (AMARC Alc), responsável pela condução política das ações da entidade. De acordo com o site da entidade, a AMARC congrega quase 4 mil associados em 150 países dos cinco continentes e se define como um movimento cidadão, político e comunicacional que trabalha como uma rede de "coordenação, cooperação, consulta, intercâmbio e promoção", tendo o objetivo de "apoiar e contribuir para o desenvolvimento da rádio participativa e comunitária sob os princípios da solidariedade e cooperação internacional"’.

Apesar de o continente ser o berço do movimento mundial, somente em 1990 é que se constituiu a AMARC Alc, através de um escritório regional em Lima, no Peru, que, em 1994, seria transferido para Quito, no Equador. Nesses anos, o foco de atuação foi a oferta de serviços para as rádios comunitárias, entre boletins, produçôes radiofônicas, pesquisas, além de dar início, em 1995, à agência regional de notícias Pulsar. A perspectiva de um escritório regional central forte gerou a crítica de uma base (rádios) enfraquecida e assistencializada.

No Brasil, a AMARC tem início através da militância do radialista carioca Marcus Aurélio de Carvalho, então coordenador do setor de rádio da ONG Ibase (CRIA, que depois se transformaria no CRIAR Brasil), através do qual conheceu a AMARC. Em entrevista para o autor, conta que já havia tido contato com o movimento de rádios livres nos anos 1980, mas que nunca lhe seduzira por não parecer "um projeto político consistente", preferindo "atuar num movimento de rádios que fosse construtor de experiências coletivas", como nos espaços políticos que conhecia: associaçáo de bairro, movimento 
estudantil e Partido dos Trabalhadores (e com o qual viria a romper já nos 1990) (CARVALHO, 2016). Ainda que militasse desde 1990, foi num seminário promovido em Quito, em 1994, que seria articulada a criação da AMARC no Brasil. Para isso é criada, em janeiro de 1995, uma ONG embrião, a AMARCUnirr, já tendo como sócios o CRIAR Brasil, CEMINA, as rádios Tan-Tan e Regional Cícero Dantas. Meses depois, a Ar Livre e Novos Rumos também se associam (em 2002, a AMARC Brasil se autonomizaria de vez).

A partir do final da década de 1990, a AMARC Alc passa por uma reflexão interna e reestruturação de sua própria autoconcepção, passando a entender-se como um movimento social, político e cultural e buscando maior incidência política na região. Para muitos, se tratou de uma "refundação" da entidade, que culmina com a mudança de sua sede regional para Buenos Aires, na Argentina. Nas palavras de um dos responsáveis por esse processo, Ernesto Lamas, coordenador regional da AMARC Alc de 2003 a 2011: "a descentralização do trabalho é uma característica estratégica do período de refundação iniciado em nível latino-americano, em 2003. A descentralização nega a ideia de uma coordenação executiva centralizada, ao mesmo tempo em que nega a ideia de que só um tipo de expertos podem levar adiante processos de gestão eficazes" (2011, p. 6). Um "trabalho desde baixo para cima" teve como um de seus pilares a criação de uma metodologia própria que fomentasse a crítica e (re)construção do projeto político-comunicacional de cada rádio comunitária da rede. Tal processo acontecia de forma participativa com os membros da emissora e da comunidade, a partir do método freireano, levando em conta a realidade e os saberes do entorno. No final da década de 1990 e na seguinte, essa metodologia foi aplicada em dezenas de oficinas realizadas em todo o continente, a partir de facilitadores e facilitadoras que, funcionando como multiplicadores, garantiriam a sustentabilidade da iniciativa.

Uma característica importante é que, desde o início, a AMARC congregou diferentes atores, entre entidades (rádios comunitárias e livres, centros de produção, organizaçôes não governamentais, rádios universitárias e públicas etc.) e pessoas (ativistas, pesquisadores etc.), ainda que somente as entidades tenham direito a voz e voto, enquanto os associados individuais têm direito somente a voz. Isso reflete e conforma um espaço de articulaçáo da grande variedade de experiências em comunicação comunitária existentes no mundo e que a AMARC abarca e quer abarcar. Até hoje: quando questionado se a AMARC, enquanto movimento, engloba (ou deve englobar) o de rádios livres, seu secretário mundial, Francesco Diasio (2015), entende que a associação deve fazer e ser uma sintese da diversidade essencial das rádios comunitárias. E vai além, demandando que a AMARC seja "trade union" [federação de sindicatos] entre instâncias fortes de um lado e necessidade de buscar um acordo - em meio à diversidade - de outro. 


\section{Considerações finais}

Ainda em sua pesquisa, Pulleiro (2011), ao analisar os diferentes termos empregados na América Latina, identifica uma vigência que começa com rádio popular e alternativa até chegar à rádio comunitária e cidadã. Não se trata de mera sucessão terminológica: cada qual representa e responde a um determinado momento político da regiáo e das rádios comunitárias. Nas experiências do primeiro momento (1940-1970), a rádio popular e alternativa quer expressar o homogêneo, a partir de um setor organizado da classe operária ou da comunidade eclesial, mesmo que implique "homogeneizar o heterogêneo" em favor do projeto (político) comum, notadamente de inspiração socialista. A partir dos 1980, o termo comunitária procurará "unir o disperso", mas mantendo suas singularidades: "se a maioria das experiências surgidas nos '60/'70 estiveram impulsionadas por quadros marxistas e cristáos, as rádios que expressam esta perspectiva [comunitária] terão como protagonistas grupos [...] que farão comunicação alternativa desde outro lugar e com outros objetivos" (p. 86). Além da ideia de uma rádio para construir e "servir a comunidade", esse conceito procura abarcar um leque mais amplo de atores e carrega bandeiras como participação, democratização da comunicação, pluralidade/diversidade e minorias (sexuais, étnicas, religiosas etc.). É quando "começa a aparecer no campo da rádio alternativa um enfoque que vai se distanciando do plano das desigualdades sociais, econômicas, políticas para trabalhar fundamentalmente no terreno da diversidade e sua possibilidade de expressão e reconhecimento" (p. 92, grifo meu). Na década seguinte, haverá ainda um estímulo para a rádio comunitária se constituir enquanto peça democrática, mediando vozes da comunidade com os poderes constituídos (principalmente públicos). As rádios tenderão a voltar-se mais ao seu projeto político-comunicacional que ao macroprojeto político.

Sem podermos negar a influência internacional(ista), é preciso relativizar a ideia de mera "transferência" (Pulleiro utiliza o verbo trasladar, em castelhano) do conceito de comunitário para a América Latina, ao menos no caso brasileiro: vimos que a ideia de "criar comunidades" encontra terreno fértil entre nós, através das experiências das CEBs e rádios de alto-falante das periferias urbanas; também a perspectiva freireana já era sólida nas nossas rádios populares e de base, assim como a estrutura organizativa comunitária. Melhor, então, falar em sincronia do ideário comunitário ao desembocar em plena época da nossa discussão legal.

Em meio à multiplicação das rádios de baixa potência e da repressão estatal, o processo de legalização da radiodifusão comunitária no Brasil (19921998) colocou à mesa de negociação atores bastante diversos. Ainda que seu detalhamento escape de nosso objetivo aqui, seu marco é o projeto de Lei da Informação Democrática (LID), que passaria a tramitar em 1992. Em meio a muitas ambiçóes, seu artigo $8^{\circ}$ contemplava a vertente livre (regulação mínima) ao prever "liberdade de emissão, transmissão e retransmissão por meio de onda eletromagnética e por fio, para emissoras de rádio e TV de âmbito 
municipal sem fins de lucro e de baixa potência, mediante registro em cartório local", excluídas as religiosas ou político-partidárias. O posterior abandono da LID apartaria as livres da negociação e do restante do movimento. Andriotti (2004) avalia ter faltado às livres a "experiência de negociação política" que "FNDC, FDC, UCBC, FENAJ etc. possuem de sobra”. Para a autora, tais entidades viam "que o discurso defendido pelas rádios livres não conseguiria ir muito longe no jogo político, a despeito da legitimidade de suas reivindicaçóes, a começar pelo próprio conceito de 'rádio livre', que dá margem ampla e sem limites, para as apropriaçóes e os usos desse meio" (p. 116). É quando "o projeto de tornar as rádios legalmente constituídas toma a forma de um movimento de rádios comunitárias" (idem, p. 124).

A partir daí a influência da vertente comunitária passa a ser definidora: basta dizer que um dos projetos apensados ao projeto de lei que conformaria a Lei 9.612/98, de radiodifusão comunitária, teria como base a lei colombiana (considerada a mais avançada da época na América Latina), contando com a colaboração de Marcus Aurélio de Carvalho e Taís Ladeira, da AMARC, e valorizando também o acúmulo (e contando com apoio político) da vertente popular e de base (eclesiástica).

Sem dúvida, a Lei 9.612 está longe de ser uma síntese democrática das diferentes forças daquele momento histórico. Fundamentalmente, é resultado do poder mutilador de um poderoso lobby empresarial (liderado pela Associação Brasileira de Emissoras de Rádio e TV) amparado por um governo neoliberal e agindo sobre um congresso subserviente e com interesses particularistas no tema. Porém, nos antecedentes da lei é possível catar concepçôes e intençóes que, em parte, explicam o seu resultado: no fim das contas, ainda que deformado, na letra da lei "venceu" um modelo de entendimento de rádio comunitária como ente comunitário, representativo e mobilizador: típico modelo organizativo de ação política hegemônico da época. Porém, ainda que a lei tenha tido forte caráter modelador para a radiodifusão comunitária brasileira, na realidade, diferentes modos e modelos coexistem.

Por isso, cabe ressaltar que o que (razoavelmente) consensuamos e entendemos por "rádios comunitárias" é resultado de um processo histórico, dinâmico e ainda em disputa sobre um modo de se agir politicamente tendo o rádio como instrumento, plataforma ou fim: trata-se de fenômeno vivo, atuante, indeterminado e internamente bastante heterogêneo. Também não é nosso escopo aqui, mas uma especificação dos principais tipos de rádios comunitárias brasileiras deveria partir dos diferentes modos de ação política (de tendência mais anarquista, socialista etc.) que as inspiram e (mais ou menos) as diferenciam entre si (e, até certo ponto, advêm das influências das três vertentes): rádios de tendência mais libertária e horizontal, outras mais centralizadas e representativas, rádios pastorais e politizadoras etc. Isso nos permitiria melhor compreender sua real heterogeneidade, suas distorçôes e como, na prática, esses diferentes modos coexistem e se retroalimentam sob a capa da ilusória síntese do comunitário. 


\section{Referências bibliográficas}

BANDRIOTTI, C. D. O movimento das rádios livres e comunitárias e a democratização dos meios de comunicação no Brasil. Dissertação (Mestrado em Sociologia) - Instituto de Filosofia e Ciências Humanas. Campinas: Unicamp, 2004.

CEMINA - Comunicação, Educação e Informação em Gênero. Irradiando juventude nas ondas comunitárias. Rio de Janeiro, CEMINA, 2000.

COELHO NETO, A. Rádio Comunitária Não é Crime-Direito de Antena: O Espectro Eletromagnético como um Bem Difuso. São Paulo: Ícone, 2002.

COGO, Denise. No ar... uma rádio comunitária. São Paulo: Paulinas, 1998.

FÁVERO, O. MEB - Movimento de Educação de Base, primeiros tempos: 1961-1966. Trabalho apresentado no V Encontro Luso-Brasileiro de História da Educação, realizado em Évora, Portugal, de 5 a 8 de abril de 2004.

FESTA, R. Movimentos sociais, comunicação popular e alternativa. In: FESTA, R. e LINS, C. E. L. Comunicação popular e alternativa no Brasil. São Paulo: Paulinas, 1986.

FESTA, R. e LINS, C. E. L. Comunicação popular e alternativa no Brasil. São Paulo: Paulinas, 1986.

FREIRE, P. Pedagogia da autonomia: saberes necessários à prática educativa. Sáo Paulo: Paz e Terra, 2002.

GUATTARI, F. e ROLNIK, S. Micropolitica: cartografias do desejo. Petrópolis: Vozes, 1986.

MACHADO, A.; MAGRI, C.; MASAGÃO, M. Rádios livres - a reforma agrária no ar. São Paulo: Editora Brasiliense, 1987.

MEB.Viver é lutar. Outubro de 1963.

. Conclusóes do $1^{\circ}$ Encontro Nacional de Coordenadores. Recife, 5 a 15 de dezembro de 1962. Mimeo.

MENDEL, Tony. Tuning into development: an international comparative survey of community broadcasting regulation. Paris: UNESCO, 2013.

MOREIRA, S. V. Rádio palanque. Rio de Janeiro: Mil Palavras, 1998.

NARAH, C. M. L. Rádio institucional e rádio livre: rupturas no modelo comunicacional dominante. Dissertação (Mestrado em Sociologia Política). Florianópolis: UFSC, 1988.

NUNES, M. A. M. Rádios livres: o outro lado da voz do Brasil. 1995. Dissertação (Mestrado em Ciências da Comunicação). São Paulo: Escola de Comunicaçóes e Artes da USP, 1995.

PULLEIRO, A. La radio alternativa en América Latina: debates y desplazamientos en la década de 1990. Buenos Aires: UBA. Facultad de Ciencias Sociales. Carrera de Ciencias de la Comunicación, 2011. 
TREVISAN, L. e PRADO, J. P. Como montar uma rádio comunitária. Macapá: Grupo de Trabalho de Rádios Comunitárias do Estado do Amapá, 1998. Mimeo.

\section{Entrevistas}

ABREU, C. Entrevista sobre a história das rádios livres no Brasil, concedida por Skype a João Paulo Malerba em 25 de junho de 2016.

CARVALHO, M. A. Entrevista sobre a AMARC Brasil e a história das rádios livres e comunitárias no Brasil, concedida a João Paulo Malerba por Skype em 21 de junho de 2016.

DIASIO, F. Entrevista sobre a AMARC Mundial concedida a João Paulo Malerba em Santiago (Chile), em 30 de maio de 2015.

LADEIRA, T. Entrevista sobre a história do movimento de rádios livres e comunitárias concedida a João Paulo Malerba em outubro de 2015.

\section{Notas}

1. É essa a organização histórica também proposta por Cogo (1998), em duas vertentes, "Católica" (p. 58-62) e "Sindical" (p.63-66).

2. Isso se verifica ao varrermos um livro importante para a área, a compilação organizada por Festa e Lins (1986) que diagnostica o estado da arte da comunicação popular no "período compreendido entre 1968 e 1983" (p.5): fala-se em imprensa sindical (p. 80-99), vídeo (p. 164-170) e até oferece um guia para uma gráfica artesanal (p. 212-222); mas as raras mençóes à comunicação popular no rádio tratam - superficialmente - do caso das CEBs e nada mais.

3. A partir de nossa revisão bibliográfica e de entrevistas com pioneiros no movimento (ABREU, 2016; CARVALHO, 2016; LADEIRA, 2015), a primeira rádio livre sindical teria sido a Rádio Tereza, do Sindicato dos Bancários de Sáo Paulo, criada em 1985. O Manifesto da rádio explica que a ideia surgira da cobertura que a Xilik fez da greve dos bancários de setembro de 1985, mas teria como base o serviço de alto-falantes móvel do Departamento Cultural do sindicato, desenvolvido entre 1981/82 (MACHADO et al., 1986, p. 123-124). Também o sistema de outorgas era um impeditivo real: por exemplo, de acordo com Moreira (1998), o Sindicato dos Metalúrgicos de São Bernardo do Campo, desde 1980, quando era dirigido por Lula, já "possuía equipamentos, instalações físicas e programação prontos para entrar no ar" (p. 107): o problema era a concessão, nunca liberada.

4. As principais experiências partiram da iniciativa de militantes partidários que já faziam parte do movimento de rádios livres e numa perspectiva eleitoreira. Nas eleições de 1985, estudantes da Universidade de São Paulo colocaram no ar a rádio Se Ligue, Suplicy (MACHADO et al., 1986, p. 43). Em 1986, surge a Rádio Dengue, no bairro da Barra Funda, operada por militantes do Partido dos Trabalhadores, já com jornalismo na programação. Além delas, pipocaram aqui e acolá rádios engajadas nas disputas eleitorais. Ainda em 1986, o PT lançaria uma livre com fins eleitorais em Belo Horizonte e outra em Florianópolis, a Trimilic, uma, digamos, filial da Xilik (cf. MOREIRA, 1998, p. 97-98). A primeira livre 
do Rio, a Frívola City se engaja na candidatura de Gabeira (pela coligação PT e Partido Verde) (NARAH, 1988, p. 178). Setores do PT chegaram a discutir a "possibilidade de se constituir uma rádio do partido" (MACHADO et al., 1986, p. 43), não concretizada.

5. Com o lema "saber, viver e lutar", o MEB continua realizando ações de educação popular no Norte e Nordeste do Brasil (cf. www.meb.org.br). Um rico repositório de seus materiais históricos está disponível em http://forumeja.org.br/book/export/ $\mathrm{html} / 1435$. Acesso em 4 de junho de 2016.

6. Disponível em http://amarc.org/?q=node/5. Acesso em 7 de julho de 2016. 